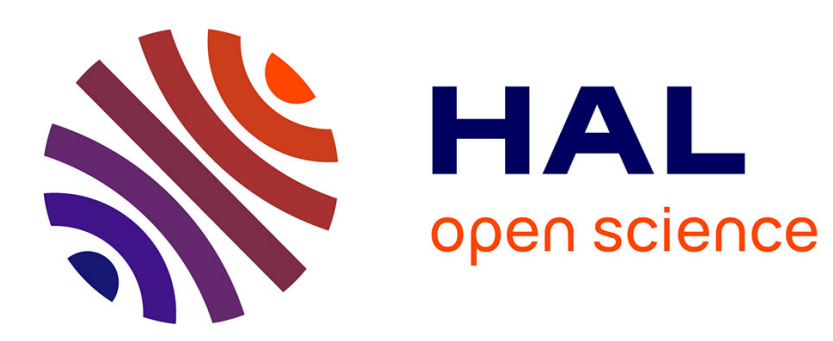

\title{
EXAFS Evidence of a Phase Transition in Icosahedral AlLiCu Quasicrystals under High Pressure
}

\author{
A. Sadoc, J. Itié, A. Polian, S. Lefebvre
}

\section{To cite this version:}

A. Sadoc, J. Itié, A. Polian, S. Lefebvre. EXAFS Evidence of a Phase Transition in Icosahedral AlLiCu Quasicrystals under High Pressure. Journal de Physique IV Proceedings, 1997, 7 (C2), pp.C2-991C2-992. 10.1051/jp4:19972110 . jpa-00255168

\section{HAL Id: jpa-00255168 https://hal.science/jpa-00255168}

Submitted on 1 Jan 1997

HAL is a multi-disciplinary open access archive for the deposit and dissemination of scientific research documents, whether they are published or not. The documents may come from teaching and research institutions in France or abroad, or from public or private research centers.
L'archive ouverte pluridisciplinaire HAL, est destinée au dépôt et à la diffusion de documents scientifiques de niveau recherche, publiés ou non, émanant des établissements d'enseignement et de recherche français ou étrangers, des laboratoires publics ou privés. 


\title{
EXAFS Evidence of a Phase Transition in Icosahedral AlLiCu Quasicrystals under High Pressure
}

\author{
A. Sadoc***, J.P. Itié ${ }^{* * * * * *}$, A. Polian****** and S. Lefebvre** \\ * Laboratoire de Physique des Matériaux et des Surfaces, Université de Cergy-Pontoise, \\ 49 avenue des Génottes, 95806 Cergy cedex, France \\ ** LURE, Université Paris-Sud, 91405 Orsay cedex, France \\ *** Physique des Milieux Condensés, Université Pierre et Marie Curie, 75252 Paris cedex 05, France
}

\begin{abstract}
In situ EXAFS studies, performed at the $\mathrm{Cu} \mathrm{K}$ absorption edge, are reported for icosahedral $\mathrm{Al}_{6} \mathrm{Li} 3 \mathrm{Cu}$ quasicrystals from ambient pressure up to $33 \mathrm{GPa}$. The increase in the average distance of first neighbours around $\mathrm{Cu}$ atoms above $20 \mathrm{GPa}$ is interpreted as the finger-print of a phase transition, while the evolution of the disorder parameter could be the signature of phason disorder.
\end{abstract}

\section{INTRODUCTION}

While extensive attention has been paid to the thermal stability of quasicrystals (QC), few investigations of their stability under high pressure have been reported. EXAFS [1] and X-ray diffraction [2] studies of icosahedral $\mathrm{Al}_{62} \mathrm{Cu}_{25.5} \mathrm{Fe}_{12.5}$ quasicrystals have shown that the AlCuFe alloy is remarkably stable with pressure up to $35 \mathrm{GPa}$. In this paper, in situ EXAFS studies above the $\mathrm{Cu} \mathrm{K}$ absorption edge of icosahedral $\mathrm{Al}_{6} \mathrm{Li} 3 \mathrm{Cu}$ quasicrystals reveal a phase transition under high pressure in quasihydrostatic conditions and at room temperature, Details will be given elsewhere [3].

\section{EXPERIMENTAL}

The icosahedral $\mathrm{Al}_{6} \mathrm{Li}_{3} \mathrm{Cu}$ alloy (T2 phase) was prepared at the Laboratoire de Physique des Solides (Orsay, France). The EXAFS experiments, carried out at LURE using the DCI storage ring, were recorded, in the energy dispersive mode, on the experimental station D11 with a Si 111 bent crystal. A fused silica mirror was used to reject harmonics. The pressure inside the diamond-anvil cell was measured by the shift of the luminescence peaks of a ruby chip added to the sample and was increased up to $33 \mathrm{GPa}$. Silicone oil was used as pressure transmitting medium.

$\mathrm{X}$-ray diffraction experiments carried out on the same quasicrystal have been reported previously [4]. They have shown that the structure remains quasicrystalline up to $17 \mathrm{GPa}$, above $17 \mathrm{GPa}$, a new structure appears. After release of the pressure, the diffraction spectrum is different from the initial one but it evolves with time since it was found different about one weak later. The remaining peaks are so broad and weak that they make impossible the determination of the final structure.

\section{RESULTS AND DISCUSSION}

After standard data reduction, the EXAFS oscillations $\chi$ were obtained versus the wavevector $k$ and Fourier-transformed to $R$ space. The Fourier-filtered spectra of the first neighbours (fig.1) shift to higher $k$ values when the pressure $P$ is increased up to $12.4 \mathrm{GPa}$, but to lower $k$ values when $P$ is increased above $20 \mathrm{GPa}$. After release of the pressure, the spectrum is found at lower $k$ values than before pressurization, but recovers its initial position one day later, showing thus "metastable" properties which were not found in our previous study of AlCuFe. Then, we have obtained the variation with pressure of $R$ (fig.2), the mean distance of first neighbour atoms around $\mathrm{Cu}$ atoms and of the corresponding disorder parameter, $\sigma$. The mean interatomic distance shortens as the pressure increases from ambient to $12.4 \mathrm{GPa}$, which is consistent with a compression of the material, does not vary much in the $13-20 \mathrm{GPa}$ pressure range but rises up to $2.55 \AA$ when the pressure increases from $20 \mathrm{GPa}$ to $33 \mathrm{GPa}$. This increase is by no means consistent with the compression of the material and is a finger-print of a phase transition. From figure 2, similar tendancy in the evolution of $R$ and $\sigma$ appears with a noticeable sharp increase of $\sigma$ at $23 \mathrm{GPa}$. Some modifications occur also in the Fourier-transforms for the higher shells, in this pressure range.

The mean interatomic distance and the disorder parameter increase all together when the pressure is released, which is consistent with a decompression of a material without phase transition. Moreover, the mean distance was found higher than at the beginning of the experiment and recovered almost its initial value only one day after. When the pressure comes back to zero, the disorder parameter has a value larger than at the beginning of the experiment $(\sigma=0.13 \AA)$, but decreases down to $0.123 \AA$ one day later when the first distance recovers its initial value. Such a kinetics effect was also observed in the diffraction experiments [4]. An explanation of the correlated increase of $R$ and $\sigma$ for $23 \mathrm{GPa}$ could be that, as the sample is 
compressed, the interatomic distances within the first shell decrease until a point is reached where the inteatomic repulsion is very great. At this point, the atoms in the first shell can be repacked more efficiently by incorporating atoms coming from outer shells. The correlated increase of $\sigma$ could be due to a softening of the intatomic forces which allows the rearrangement of the first shell.

Icosahedral quasicrystals may be described by a periodic structure in a six dimensionnal (6D) space, composed of the 3D physical space, or parallel one, and of the 3D complementary space, or perpendicular one. Atomic hopping (so-called phason dynamics) is a specific defect in the perpendicular space. These jumps could constitute a mechanism for a novel, fast diffusion process. They also could be the elementary process for the phase transitions between quasicrystals and related phase to occur. Is the phase transformation observed here assisted or not by phasons flips introduced during the compression? In other words, is there in the disorder parameter $\sigma$ a component due to phasons? The answer is not straightforward, since we are not able, in the EXAFS analysis, to distinguish between a disorder parameter due to phonons or to phasons. However, it has been shown that the dynamic part should decrease with $P$ [5]. The fact that $\sigma$ is almost constant up to $13 \mathrm{GPa}$ could mean that there is a phason component which balances this decrease. This was already observed in AlCuFe [1].

A Mumaghan equation of state was adjusted to the values of distances: $\mathrm{d} / \mathrm{d}_{0}=\left(1+\mathrm{PB}_{0} / \mathrm{B}_{0}\right)^{-1 / 3 \mathrm{~B} 0^{\prime}}$, where $B_{0}$ is the bulk modulus associated to the considered distance, and $B_{0}$ ' its pressure derivative. The local compression of the shells of neighbours surrounding $\mathrm{Cu}$ atoms are thus characterized by $B_{0}=71 \mathrm{GPa}$ for $B_{0}{ }^{\prime}=6$. The $B_{0}$ local value found here around $\mathrm{Cu}$ in $\mathrm{AlCuLi}$ differs significantly from the overall bulk modulus value for pure copper, but is close to its value for pure aluminium $\left(B_{0}=72.8 \mathrm{GPa}\right.$ in $\mathrm{Al}$ and $133 \mathrm{GPa}$ in $\left.\mathrm{Cu}[6]\right)$.
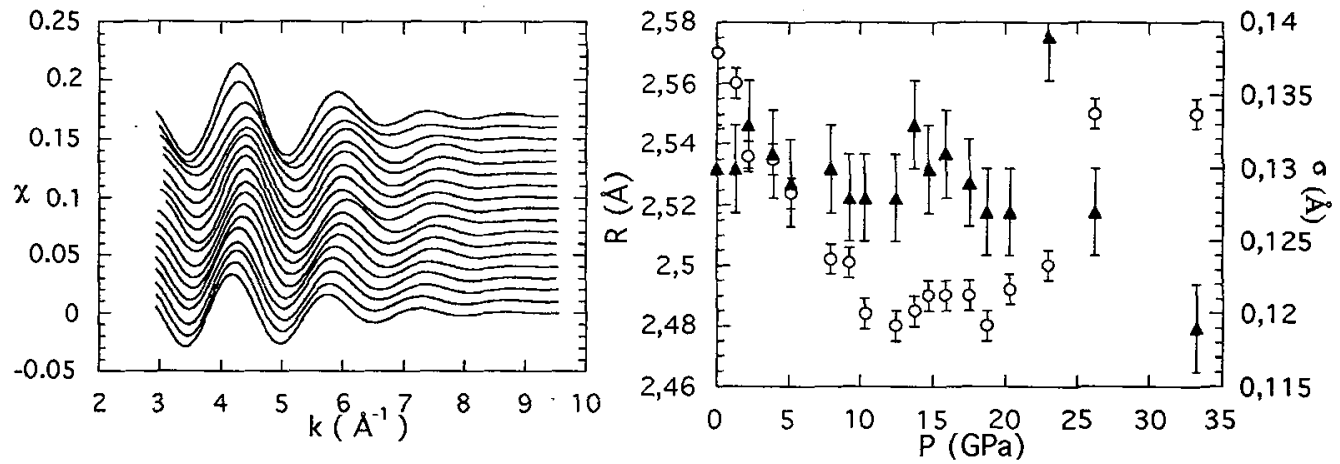

Figure 1 - Evolution with increasing pressure $P$ of the Fourier filtered first shell above the $\mathrm{Cu} \mathrm{K}$ edge; from bottom to top: 0 , $1.3,2.2,3.9,5.1,7.9,9.2,10.3,12.4,13.7,14.7,15.9,17.5,18.7,20.3,23,26.2,33.2 \mathrm{GPa}$.

Figure 2 - Variation of the first neighbour mean distance (circles) and of the disorder parameter (triangles) with $P$.

\section{CONCLUSION}

We have studied, by in situ EXAFS experiments above the $\mathrm{Cu} \mathrm{K}$ absorption edge, the effect of pressure on an AlCuLi icosahedral alloy in quasihydrostatic conditions. A phase transition was detected for pressures above $20 \mathrm{GPa}$ in contrast with $\mathrm{AlCuFe}$ alloys which remain icosahedral up to $35 \mathrm{GPa}$. However, in both types of quasicrystals, the anomalous small variation of the disotder parameter could be an experimental signature of phason defects.

\section{References}

[1] Sadoc A., Itié J. P.,Polian A., Lefebvre S., Bessière M. and Calvayrac, Y., Phil. Mag.B 70 (1994) 855-866.

[2] Lefebvre S., Bessière M., Calvayrac Y., Itié J.P., Polian A. and Sadoc A., Phil. Mag.B 72 (1995) 101-113.

[3] Sadoc A., Itié J.P., Polian A. and Lefebvre S., Phil. Mag. A (1996) in press.

[4] Itié J.P., Lefebvre S., Sadoc A., Capitan M., Bessière M., Calvayrac Y. and Polian A., "X-ray absorption and diffraction study of the stability of two quasicrystals (AlCuFe and $\mathrm{AlCuLi}$ ) under high pressure", Proceedings of the Fifth International Conference on Quasicrystals, Avignon, 22-26 may 1995, C. Janot and R. Mosseri Eds. (World Scientific, 1996) pp. 168-171.

[5] Freund J., Ingalls R. and Crozier E.D., Phys. Rev. B 39 (1989) 12537-12547.

[6] Young D. A., Phase diagrams of the elements, 1991, University of California press, p. 273. 